\title{
Managerial and Leadership Perceptions of CEOs in Leading Turkish Companies
}

\author{
Ali Akdemir \\ Department of Business, Faculty of Business Administration and Economics \\ Canakkale Onsekiz Mart University \\ Biga 17200, Turkey \\ Murat Kasimoglu \\ Department of Business, Faculty of Business Administration and Economics \\ Canakkale Onsekiz Mart University \\ Biga 17200, Turkey \\ Tel: 90-5363-382-404Ｅ-mail: mkasimoglu@yahoo.co.uk \\ Asli Ekmekci \\ Department of Business, Faculty of Business Administration and Economics \\ Marmara University \\ Istanbul, Turkey \\ Tel: 90-5323-216-863Ｅ-mail: aslikucukaslan@yahoo.com
}

\begin{abstract}
The aim of this study was to examine the factors affecting the management and leadership style and managerial perceptions of managers in leading Turkish companies. The empirical research was conducted with the participation of top-level managers in the top 500 companies of Turkey and the data was statistically analyzed using the Poisson Regression Model. As a result of the analysis of the data, it was found that the number of employees working in the organization and the leadership and management styles of the managers, have significant effects on managerial perceptions of the managers. Therefore, it is suggested that the study will enable an understanding of the decision making processes of top management in Turkey.
\end{abstract}

Keywords: Management, Leadership, Managerial perception, Turkey

\section{Introduction}

Managers are one of the main factors that affect the success of organizations because they participate and work through the decision-making processes and have a significant influence during the organizational resource planning process. Within this framework, studies on managers' effective decision-making processes tended to focus especially on the trait theory. In the trait theory, individual factors were considered and the impact of the physical traits of the managers on the managerial processes was examined. Historically, this approach can be viewed as normal because of situational factors; it can also be said that in previous times there were no other effective factors when the subject is evaluated from the viewpoint of the managers' power source.

When this issue is evaluated historically, it can be seen that there were very successful and effective leaders, managers, kings, and strategy developers who actually applied modern management approaches. Therefore, when considering management and managerial practices, these should be assessed more widely and more rationally. In this context, it is important to find out the common values of the success of leaders throughout the centuries in order to help identify contemporary management models.

However, the process of management studies and researches occurred differently. After the theory of the "big man", the subject was examined using behavioral models. Hence, management practices were considered within organizational 
parameters and studies especially focused on the attitudes and behaviors of managers towards production factors. Therefore, the field of management and subject of managerial practices gained new dimensions and fresh, in-depth studies on the attributes of the general behaviors of a successful management model towards production factors were carried out. Researches were conducted in two dimensions. Before all else, a management evaluation scale was developed in order to measure how a manager acts and performs in his position. This scale was used to identify managerial characteristics from the view of employees and how the employees perceived their managers' acts and attributes could be measured with the aid of this scale. According to the findings of the scale, if the managers gained high points in the "structure" part, it meant that those managers adopted an effective process in making programs, planning, and effective communication. If their total points concerning "employee relations" were high, it meant that the managers were listening to their employees, giving them information, and trusting them. Many studies showed that giving importance to the structural and human side of the organization had positive correlations with other functions within the total organizational system.

After this, managerial studies were generally evaluated in two fields, namely, employee focused and job focused. The findings of these studies indicated three contingent factors: task structure, member-leader relation, and position power. Tasks were revealed as being "structured" and "unstructured". The tasks that had high structured property were considered as having only one method of solution and the solution was clear and evident. Leader-member relations and the manager's position were also indicated as important fields within the managerial processes. In addition, authority and power sources effective in the manager's in-group relations were found to be contingent factors which direct management processes.

The basic findings of all the management studies and researches coalesced around the same variables. The common points of the studies focused on the importance of the efficiency of managers during the decision-making processes. Especially, the resource use of organizations was considered a very important factor and a number of empirical studies were carried out on this aspect which tried to determine whether the findings supported the case or not. They concluded that existing models were inadequate to explain managerial processes and other factors also had an important effect. Despite this, all these studies and findings made an important contribution to the methodology and scientific discussion of the field. By means of these studies, management science benefited from having a well-developed model and scientific knowledge for the study of management processes emerged. These studies also contributed to the development of contemporary management models and indicated new approaches concerning today's management practices.

\section{Previous Studies on the Management Process}

When management researches are analyzed, it is seen that management models were examined in different dimensions and from different perspectives. In Bennis' (2004) studies, the common characteristics and behavioral models of managers, rather than the differences, were examined. The findings indicated that managers were individuals who do things right right jobs in organizations. Managers were considered as having an important role in the decision-making processes and that there were basic factors that enhanced their decision-making. One of the basic functions of managers in organizations is to concentrate on the performance of the team they manage and to inspire and motivate team members. Managers are individuals with a vision that enables the team members to reach their goals. According to Bennis (2004), one of the common characteristics of managers is the management of meaning. The managers empower the members' creativeness by means of which the members to participate in the processes and share the vision. Managers have to connect with the members' visions and the interaction that emerges leads to employees working collectively towards a common goal. Managers have to rationalize their ideas and thoughts for members of the organization and should communicate them clearly by using analogy and metaphors. An important characteristic of managers is the management of trust relations within the company. The most important property of trust is being considered trustworthy by others. This can be defined as exhibiting the same behaviors and attitudes in every circumstance. In executing the job process, being conscious of their skills during the decision-making processes and developing these skills efficiently are very important for the managers and employees. It has been emphasized that management is a process perceived by the entire workforce of the organization and which enhances collective effort, good mutual relations, and energized employees. In the organization, empowerment has a crucial role and collective effect on all employees. As a consequence of empowerment, employees feel important because they belong to a group, and opportunities for their learning and skills development are given.

All these factors indicate different dimensions of the management process and designate the variables which affect the organization and leader relationship. These factors are also important for directing the strategic decisions of managers and allowing those strategies to have an impact. Zaleznik (2004) emphasizes that the most important factor about being a manager is having "dreams". According to him, this means having the ability to transform a problem or difficulty into an opportunity. Briefly, this process means motivating others to solve problems within the organization. According to this approach, creating opportunities and finding solutions to problems are the most important factors. Being an 
opportunist makes managers express their visions practically, and being optimistic helps them to shape the members' vision. Tichy and Devanna (1995) state that in today's business world, good management is required more than ever, and they evaluated the general characteristics of managers as follows. Managers define themselves as transformative. It is a reality that the most important part of the management process is creating and implementing the change process and making effective transformations. Today, organizations need these to survive and develop competitive advantages. Creating an organizational image and differentiating the company in the market are the responsibility of managers and depend on their skills. The managers empower employees and encourage them to take risks. In order to enable this, employees are given autonomy and supported in different operations. One of the most important factors in the management process is trust in others. Here, it can be understood that being a manager does not mean being a dictator, because managers always hold the ultimate power, but they should be sensitive towards others and tend to empower followers.

Managers learn continuously and do not see their actions or concepts which do not produce the desired result as problems which cannot be overcome. They learn from their experiences and add what they have learned to their behavioral processes.

Golman (2000) offers a different perspective on the subject. In his study, he states that intelligence, seriousness, and vision are all important factors for success but not enough to explain the whole management process. According to his view, the most important factor that distinguishes an effective manager from others is emotional intelligence. Emotional intelligence can be defined as self-regularity, consciousness, self-motivation, empathy and social skills. The findings of his research significantly support an association between emotional intelligence and managerial outcomes.

Moreover, it is found that employees, customers, and other shareholders have many problems in and with organizations where the leaders of the organization have low emotional intelligence. The consequence is dissatisfied employees, customers, and shareholders and the entire process of the organization is affected negatively. Many examples of this situation are to be found in the business world.

Zaleznik (1995), states that there are three factors - motivation, vision, and passion - which have crucial roles in creating managerial success. These factors have impacts on organizational success and importance for successful management. Zaleznik also suggests that being a manager and being a leader are very different concepts and they should be evaluated differently. Leaders have the ability to manage ambiguities and uncertainties; they motivate others in difficult conditions and perceive events astutely. In this context, the basic factor for organizational success is the ability of leaders and managers to work together synchronously.

Boehnke et al. (2003) studied whether management behaviors are universal or not and they evaluated the impact of cultural differences on the management process. According to the empirical findings of their research, there are some basic management characteristics for a high level of organizational success. These characteristics are; creating a vision, intellectual orientation, team development, and coaching. Pillai and Williams (2004) identified a different dimension of management in their research. They propose that managers have a crucial role in stimulating employees to be more productive and in producing meaningful outcomes. They determined a significant association between organizational commitment and performance in their research. These findings were supported by empirical research on fire department personnel. According to Kass and Shamir (2004), there is strong emotional relationship between managers and employees. This approach is the opposite of the cognitive theory. There are not many empirical researches on this approach, and these studies generally test their hypotheses by evaluating the depth of the emotional relationship between managers and employees.

There have also been studies examining the relationship between management characteristics and team performance (Dionne \& Yammarino, 2004). It was found that the managers' influence on the motivation process creates a shared vision within the organization, strengthens team spirit, empowers team members, and thus decreases conflict among team members. Apker (2004) did another specific study in which she examined the collaborative aspect in the health sector. Apker's study emphasizes the positive relationship involved in a team-based process which shifts organizational control from management to employees but results in workers acting in accordance with management decisions and upholding traditional power structures. Kark (2004) examined the subject from the point of view of women. It was determined that women have replaced men in today's business world. Other recent studies have attempted to find out whether there is a significant relationship between gender and management. Chakraborty and Chakraborty (2004) analyzed management from the perspective of psychology and considered a different dimension of management. This study implies the importance of management for both morale and motivation within the organization. Gosling and Mintzberg (2003) examined the issue from the point of view of the organization. They gathered all managerial fields under five factors, as follows; the manager him/herself, organizations, content-procedures, relations, and change. Goleman (1998) argued that there are no significant findings which show that any management model has definite and absolute consequences. However, recent research carried out on 3871 managers demonstrated that the six different dimensions of emotional intelligence have positive impacts on the management processes. In the context of these six 
dimensions, the "coercive manager" wants others to obey instructions immediately; the "autocratic manager" directs followers towards the vision; the "democratic manager" tries to create a common background for the applications; the "creative manager" requires excellence in every area; and the "coach manager" trains individuals for the future. Goleman (2000) examined the subject in detail in other studies and stresses the importance of emotional intelligence for management models using real experiences and examples. Bartlett and Ghoshol (1995) examined the changing roles of managers and tried to redefine how managers' roles have changed in organizations. In their research, new developments in organizational structure and information flow are analyzed. Bennis (1995) examined the changing role, characteristics, and attitudes of leaders from an historical perspective. Kotter (2001), in his study, examined what managers really do in organizations and he evaluated the "manager" as a factor that creates and implements changes in the organization.

As is emphasized in many other studies, the motivating characteristics of managers have crucial importance for the organizational structure. Conger and Fulmer (2003) considered the factors that cause success and failure, and they argue that dynamic and innovative organizations are more successful than ones which have mechanical structures and processes. In organizational ecology, the determination and successful application of strategies is very important for leaders as the right strategy enables the creation of alternatives for competition and innovation. There are a number of studies in the literature which examine how the personality traits of managers affect individuals (Lansiti \& Levien, 2004) and which analyze the relation between organizational performance and managers (Thomas, 1988).

There are also studies that investigate the association between top level managers and the external environment of the organization and that examine the impact of strategies on the functioning of organizational systems. The impacts of the managers' expertise on strategy and organizational success were determined by studies carried out on managers working for the companies listed in Fortune 500 (Geletkanycz \& Hambrick, 1997). In another study, the associations of the demographic structure of the top level managers on the social integration and communication processes within the organization (Smith \& White, 1987) were investigated. A further study which examined the heterogeneity of top level managers tried to prove the significant effects of demographic structure on the organizational competition process (Smith et al., 1994). In addition to those noted, there are many other preliminary studies about the subject in the literature (Hambrik, Cho, \& Chen, 1996).

\section{Analysis of Data Structure and Research Model}

The data form developed for the research consisted of two parts. The first part involved questions about the participating managers' and companies' demographic information. In this part, the work experience, educational level and age of the managers, together with the number of individuals within the control area of the manager, were asked. The second part of the questionnaire was composed of 42 questions. The questions related to the managers' management perceptions, decision-making processes, attitudes to the job and treatment of subordinates, and concepts about strategic decision-making processes. For every question in the second part, a 5 point scale was used, from 1 (most important) to 5 (least important), and the participants were asked to list them in order. Following that, the data collected were subjected to statistical analysis.

The research was conducted among the managers working for companies that were listed in the first 500 companies of Turkey. The preferred participants were from the functional departments (marketing, production, human resources, finance) and were top-level managers (CEO). 200 questionnaires were delivered and 125 of them were answered and returned. All 125 questionnaires were able to be used in the statistical analysis.

In the analysis of the data, it was decided to use the Poisson Regression Model. According to this model, Y represents a casual variable and $i$ in each sample represents an individual. In this situation, Yi means that the event occurred in a given period of time for the unit of $i$ from the unit of $N$. Every $i$ individual includes rate parameter $\lambda$ and $x(j=1 \ldots K)$ explanatory variables.

In such events, the equation can be defined as follows (Kenneth, Land, Nagin, \& Mccall, 2001):

$$
\begin{gathered}
\lambda_{i}=\exp \left(x_{i} \beta\right) \\
\log \lambda_{i}=x_{i} \beta .
\end{gathered}
$$

By considering the above model, the equation of the study can be developed as follows. In the research, the CEOs' perception of management and leadership (CPML) was considered as a dependent variable. When the previous studies in the literature were examined, it can be seen that there were a number of factors affecting and differing from the leaders' perception of management and leadership. Therefore, this causes every leader and manager to develop a unique management style. Additionally, it is normal that the perception of each leader should be different due to human factors. In this study, we tried in particular to determine whether the number of individuals working in the company (NI), the 
leadership understanding of the manager (LU), the management style of the manager (MS), the education level (E) and the age of the manager (A) had any impact on the management style and perception of management and leadership of the managers. Those variables and the equation of the research is as follows;

$\mathrm{CPML}=\exp (\mathrm{Ni} \beta 1+\mathrm{Lu} \beta 2+\mathrm{Ms} \beta 3+\mathrm{E} \beta 4+\mathrm{A} \beta 5)$.

In the questionnaire, the participants were asked which leadership model (autocratic, intellectual, participative, contingent, or charismatic) most closely described their own style. When previous studies were examined, it was seen that each of the leadership models has different applications within the organization. Therefore, it is important to understand how different leadership models reflect management processes and this will enable a better understanding of the different management applications in the organizations. In this context, the hypotheses generated were as follows;

H1a: The leadership models of managers make a difference to their management applications. An organizational system which is managed by autocratic leaders will be more mechanical.

H1b: The leadership models of managers make a difference to their management applications. An organizational system which is managed by participative and democratic leaders will be more organic.

The managers were asked in the questionnaire about their management styles and were required to answer what kind of a style they adopted in relations with subordinates and the environment. The participants could choose one or more of the management styles directing, supporting, delegating authority, teaching, adapting to circumstances which they possessed.

H2: Having an understanding of the directing, supporting or teaching styles during the managerial processes affects the manager's perceptions of managerial processes and causes application of different managerial practices.

Other factors that affect the manager's perceptions are the number of individuals worked with or number of subordinates. There are differences in the perceptions of management and leadership between managers who work with small groups and large groups. Work processes are more complex especially in large companies and relations are more formal. Therefore, directing and controlling small groups affects and may alter the managerial style of a manager.

H3: There are differences between small, medium, and large-sized companies in terms of their managers' leadership and management styles and managerial perceptions.

In the research, educational level was considered as another factor affecting the managers' leadership and management styles and managerial perceptions. It was assumed that there would be differences between managers having high school, university, and other postgraduate level education in terms of their managerial perceptions because education is considered as an important variable which influences individuals' cognitive and behavioral processes.

H4: There will be differences between the managers having lower and higher education in terms of their leadership and management styles and managerial perceptions.

Moreover, biological age was considered another factor affecting the managers' leadership and management styles and managerial perceptions because it was assumed that the buildup of experience and knowledge causes managers to perceive events and situations in a different way. Therefore, it was expected that there would be differences between younger managers and elder managers in terms of their managerial perceptions.

H5: There will be differences between the managers' experience according to their age and accordingly there will be differences in their leadership and management styles and managerial perceptions.

\section{Findings of Research}

The findings of the research and the statistical results of the data gathered are presented below. When the associations between the variables were analyzed, either a low level of correlation or high level of negative correlation was seen. The correlations of the variables can be seen in Table 1 .

Poisson Regression Model or Log Linear Models were used in the analysis and evaluation of the data. These models are used for events occurring in a given period of time in order to see the explanatory power of the variables. In this research the explanatory variables were considered as the factors affecting the managers' managerial perceptions. This model contains countable data that are not discontinuous and negative and therefore it is assumed that the logarithm of the expected numbers is the linear function of the explanatory variables (Haining, 2003).

Poisson Regression Model is a flexible and easy-to-use model which is used in multiple models containing the mean of the countable data and when there is a moderating or marginal association between the variables (Lloyd, 1999). Due to these characteristics, this model was preferred for the statistical analysis of our research.

For analysis of the data, a macro was written using the GENMOD Procedure. The five different independent variables, involving the age and education level of managers, size of company, individual leadership perception of managers and managerial styles, were analyzed using the Poisson Regression Model. According to the findings of the Wald Test, 
among the five independent variables, the number of employees working in the company (0.0167), the leadership styles of the managers $(0.0470)$ and the management styles $(0.0397)$ were significant at $95 \%$ confidence level. The age of the manager (0.5959) and the education level (0.7124) were not statistically significant, as seen in Table 2 . This finding is interesting when the assumptions of the research are considered because previous studies in the literature determined that there are significant associations between the experience, age, and education level of managers and their managerial perceptions and leadership styles. However, according to the findings of our research, these variables had no significant impact on the managerial perceptions and leadership styles of the managers. Therefore H4 and H5 were rejected. It was seen that the other 3 hypotheses are supported by the findings because the size of the company and the leadership and managerial styles of the managers have significant affects on the management, leadership, and managerial perceptions of the CEOs. These findings are interesting considering the general context of our research (Table 2).

According to the findings of Pearson $\mathrm{X} 2$ tests, the model was not statistically significant because the Chi-square/Estimation value was greater than 1 (Chi-square/Estimation=2.6210 >1). There was a high diffusion in the Poisson Regression Model. When this occurs, a mixed model called the Poisson-Gama Regression Model can be used for the analysis. Therefore, in order to analyze the data with the Poisson-Gama Regression Model, a new macro was written using the GENMOD Procedure.

According to the Wald tests, among the five variables, the size of the company (0.0233), the leadership style (0.0475), and the characteristics of the managers (0.0463) were statistically significant at $95 \%$ confidence level.

According to the findings of the Poisson-Gamma Regression Model, the data were significant for the model (Chi-square/Estimation $=1.1093>1)$.

$$
\begin{aligned}
& \mathrm{CPML}=\exp (2.6539+\mathrm{Ks} 0.0040+\mathrm{La}(-0.0669)+\mathrm{Ys}(-0.0728)) \\
& \mathrm{CPML}=\exp (\mathrm{Ni} \beta 1+\mathrm{Lu} \beta 2+\mathrm{Ms} \beta 3+\mathrm{E} \beta 4+\mathrm{A} \beta 5) .
\end{aligned}
$$

The findings of the model were evaluated differently from the classical regression model. In the classical regression model, the coefficient of each of the variables indicates how much difference will be seen at the end of an increase of one unit. In the Poisson-Gamma Regression Model, it can be stated that there will be 1.004 increase in the model depending on one unit change occurring in the size (number of employees working) of the company. When the impact of changes in the leadership styles of the managers on their managerial perceptions was analyzed, it was seen that the leadership style impact was higher than the impact of the number of employees working in the company according to the model (2.6551). This finding is significant and also parallel with previous research findings in the literature. As determined in the literature, the leadership perceptions of managers as being democratic, autocratic, or participative have meaningful and important affects on the managerial perceptions of the managers. Another significant finding was that the managerial styles of the managers can be considered as important variables affecting their managerial perceptions. When there is one unit change in the managerial styles of the managers, there will be an effect on the perceptions of the managerial processes (2.645). It is seen that there is a significant relationship between leadership styles and managerial perceptions and this finding has importance for determining which factors are effective on the management and leadership styles and managerial perceptions of managers in organizations. The age and education level variables had no significant affect on the dependent variables; these have therefore not been explained in the findings. The findings of the variables are presented in Table 3.

\section{General Evaluation and Discussion}

This study aimed to find out which factors have impacts on the differences of management and leadership styles and managerial perceptions of managers in leading Turkish organizations. It is supposed that this research will be useful for organizational systems in various ways because both managers and employees have crucial importance for organizations. Organizations grow, develop and create competitive advantage by means of the decisions of their leaders and CEO's. In this study, the basic factors influencing the managerial perceptions of the CEO's were determined. According to the findings of the research, it is interesting that there is no significant relationship between the age and education level of the managers and their managerial perceptions. However, these variables should be tested in different samples so that different evaluations can be made and different findings may be obtained. According to the findings of this research, it is seen that leadership is the factor which has the strongest effect on the managerial perceptions of the CEO. Therefore, it is suggested that the leadership characteristics of managers should be closely evaluated during the recruitment and selection process of the organization.

Another finding is that management style has a significant effect on the managerial perceptions of the CEO. Therefore, management style can be considered as an important factor in the evaluation of managerial perceptions.

This study can be considered as the foundation of further studies we intend to carry out as it is believed that the identification of the managerial perceptions of CEO's in different dimensions has importance for organizations, and we will continue researching and examining new data on the management styles and perceptions of the CEO's. Hence, the 
reliability and validity of the variables and findings will increase and the CEOs' decisions, behaviors and attitudes will be understood better by means of further studies involving different dimensions and variables.

\section{References}

Apker, J. (2004). Sensemaking of Change in the Managed Care Era: A Case of Hospital-Based Nurses. Journal of Organizational Change Management, 17: 211-227.

Barlett, A. C., \& Ghoshal, S. (1995). Changing the Role of Top Management: Beyond Systems to People. Harvard Business Review, May-June: 132-142.

Bennis, G. W. (2004). The Seven Ages of the Leader, Inside the Mind of the Leader, Harvard Business Review. January: 46-53.

Boehnke, K., Bontis, N., Distefano, J. J., \& Distefano, C. A. (2003). Transformational Leadership: An Examination of Cross-national and Similarities. Leadership \& Organization Development Journal, 24: 5-15.

Chakraborty, S. K. \& Chakraborty, D. (2004). The Transformed Leader and Spiritual Psychology: A Few Insights. Journal of Organizational Change Management, 17: 94-210.

Cogner, A. J., \& Fulmer, M. R. (2003). Developing your leadership pipeline. Harvard Business Review, December: 76-84.

Dionne, D. S., \& Yammarino, J. F. (2004). Transformational Leadership and Team Performance. Journal of Organizational Change Management, 17: 177-193.

Dvir, T., Kass, N., \& Shamir, B. (2004). The Emotional Bond: Vision and Organizational Commitment among High-Tech Employees. Journal of Organizational Change Management, 17: 126-143.

Geletkanycz, A. M., \& Hambrick, C. D. (1997). The External Ties of Top Executives: Implications for Strategic Choice and Performance. Administrative Science Quarterly, 42: 654-681.

Goleman, D. (1998). What Makes A Leader? Harvard Business Review, November-December 93-102.

Goleman, D. (2000). Leaders That Get Results. Harvard Business Review, March-April: 78-90.

Goleman, D. (2000). What Makes A Leader? Inside the Mind of the Leader. Harvard Business Review, January.

Gosling, J. \& Mintzberg, H. (2003). The Five Minds of a Leader. Harvard Business Review, November: 54-61.

Haining, R. (2003). Spatial Data Analysis: Theory and Practice, West Nyack: Cambridge University Press.

Hambrick, C., D., Cho, S. T., \& Chen, M. (1996). The Influence of Top Management Team Heterogeneity on Firms' Competitive Moves. Administrative Science Quarterly, 41: 659-684.

Kark, R. (2004). The Transformational Leader: Who is (s) he? A Feminist Perspective. Journal of Organizational Change Management, 17: 160-176.

Kenneth C. L., Nagin, D. S., \& McCall P. L. (2001). Discrete Time Hazard Regression Models with Hidden Heterogeneity. The Semiparametric Mixed Poisson Regression Approach. Sociological Methods \& Research, 29: 351-352.

Kotter, J., P. (2001). What Leaders Really Do Breakthrough Leadership? Harvard Business Review, December: 85-97.

Lansiti, M., \& Levien, R. (2004) Strategy as Ecology. Harvard Business Review, March: 68-78.

Lloyd, C. J. (1999). Statistical Analysis of Categorical Data, New York: John Wiley and Sons.

Pillai, R., \& Williams, E., A. (2004). Transformational Leadership, Self-Efficacy, Group Cohesiveness, Commitment, and Performance. Journal of Organizational Change Management, 17: 144-159.

Smith, G., K., Smith, K. A., Olian, D. J., Sims, Jr. P. H., O’Bannon, P. D., \& Scully, A. J. (1994). Top Management Team Demography and Process: The Role of Social Integration and Communication. Administrative Science Quarterly, 39: 412-438.

Smith, M., \& White, C. M. (1987). Strategy, CEO Specialization, and Succession. Administrative Science Quarterly, 32: 263-280.

Thomas, A., B. (1988). Does Leadership Make A Difference to Organizational Performance? Administrative Science Quarterly, 33: 388-400.

Tichy, M., N., \& Devanna, A., M. (1995). The Transformational Leader The Manager's Bookshelf: a Mosaic of Contemporary Views, 244-255.

Zaleznik, A. (1995). The Managerial Mystique. The Manager's Bookshelf: A Mosaic of Contemporary Views.

Zaleznik, A. (2004). Managers and Leaders Are They Different, Inside The Mind Of The Leader. Harvard Business Review, January: 74-81. 
Table 1. Correlations of Variables

\begin{tabular}{|c|c|c|c|c|c|c|}
\hline \multicolumn{2}{|c|}{1} & \multirow[t]{2}{*}{2} & & \multirow[t]{2}{*}{3} & \multirow[t]{2}{*}{4} & \multirow[t]{2}{*}{5} \\
\hline 1 & & & & & & \\
\hline 2 & -0.6889 & & & & & \\
\hline 3 & -0.3977 & -0.0368 & & & & \\
\hline 4 & -0.1299 & -0.0423 & -0.0841 & & & \\
\hline 5 & -0.2731 & -0.0266 & -0.1093 & -0.0019 & & \\
\hline 6 & -0.2987 & -0.0884 & 0.0015 & -0.0868 & -0.0541 & \\
\hline
\end{tabular}

$\mathrm{N}=125$.

Table 2. Significance Levels of Variables

\begin{tabular}{|c|c|c|c|}
\hline & & Chi- & Pr $>$ ChiSq \\
\hline Parameter & $D F$ & Square & 0.5959 \\
\hline Age & 1 & 0.28 & 0.7124 \\
\hline Education & 1 & 0.14 & 0.0167 \\
\hline Size of company & 1 & 5.72 & 0.0470 \\
\hline Leadership style & 1 & 3.95 & 0.0397 \\
\hline
\end{tabular}

Table 3. Findings of Variables

\begin{tabular}{|c|c|c|c|c|c|c|c|}
\hline Parameter & $D F$ & Estimate & $\begin{array}{c}\text { Standard } \\
\text { Error }\end{array}$ & $\begin{array}{c}\text { Wald 95\% } \\
\text { Limits }\end{array}$ & Confidence & $\begin{array}{c}\text { Chi- } \\
\text { Square }\end{array}$ & $\operatorname{Pr}>C h i S q$ \\
\hline Intercept & 1 & 2.6517 & 0.2416 & 2.1782 & 3.1253 & 120.44 & $<.0001$ \\
\hline Age & 1 & 0.0025 & 0.0047 & -0.0067 & 0.0116 & 0.28 & 0.5959 \\
\hline Education & 1 & 0.0335 & 0.0910 & -0.1448 & 0.2119 & 0.14 & 0.7124 \\
\hline Size & 1 & 0.0040 & 0.0017 & 0.0007 & 0.0072 & 5.72 & 0.0167 \\
\hline Leaderstyle & 1 & -0.0669 & 0.0337 & -0.1329 & -0.0009 & 3.95 & 0.0470 \\
\hline \multirow[t]{2}{*}{ Mngmtstyle } & 1 & -0.0728 & 0.0354 & -0.1423 & -0.0034 & 4.23 & 0.0397 \\
\hline & 0 & 1.6189 & 0.0000 & 1.6189 & 1.6189 & & \\
\hline
\end{tabular}

